\title{
Developing Discipline among Students through Social-Emotional Learning: A New Model to Prevent and Reduce Behavior Problems
}

\author{
Lee Moi Ching*, Yeo Kee Jiar, Hadijah Jaffri \\ Universiti Teknologi Malaysia, Malaysia \\ *mclee79@hotmail.com
}

\begin{abstract}
The disciplinary problem in schools is a major concern for government, educators, parents and society in Malaysia. Knowing that discipline problems will be dealt with fairly and consistently has been shown to have a dramatic impact on student well-being and achievement. This study discussed the discipline issues in Malaysia; the affects of reactive and punitive approach; root cause attributing to the students discipline problems; how to cope with the disciplinary problems; and using social-emotional learning (SEL) to develop discipline among students. SEL is a promising approach that is able to reduce risky behaviours, increase desirable behaviours and promoting positive development.
\end{abstract}

Keywords: Discipline; Reactive and Punitive Approach; Social-Emotional Skills; Mental Health; SocialEmotional Learning

\section{Introduction}

Our education is at a critical juncture, parents and educators focus on the cognitive elements of education, while other life skills are often has been underemphasized or altogether forgotten from the in-school experience (Buffett \& Shriver, 2012). Both parents and educators want young peoples to succeed in academic, personal, and social lives (Payton, Wardlaw, Graczyk, Bloodworth, Tompsett, \& Weissberg, 2000), but in school across the country, there is a missing critical piece in education to build a holistic and healthy student - social-emotional skills. Therefore, many children become less connected to school, thus negatively affects their academic performance, behaviour and health (Blum \& Libbey, 2004). Following by this, conduct problems such as behavior problems, are externalizing problems in mental health difficulties, and a manifestation of psychological difficulties. Behavior problems take the form of discipline problem that is a common phenomenon in many schools in Malaysia. Disciplinary problem is a prevailing problem affecting the schools in Malaysia and also across the nations around the world. Disciplinary problems have a dramatically impact on students' academic performance and wellbeing, furthermore, it also interferes the teaching and learning process in classrooms. Developing discipline among students is a long-standing challenge for educators. At the heart of this challenge is the use of reactive and punitive versus supportive disciplinary practices in curbing the disciplinary problems (NASP, 2002). The legislation and research always study for best practice strategies to reduce the disciplinary problems. Such effective discipline practice can increase students' desirable behaviour, create conducive and supportive learning environment in school and classroom, build relationship among teachers and students, ensure the safety and dignity of students (NASP, 2002) and educators and develop selfdiscipline or self-management, with an aim to have long-term outcomes.

In this recent years, discipline issues has made a major concern to all party including parents, educators, government and the public alike. From minor and common discipline issues like littering to juvenile cases like rape, incest, robbery and such. Minister of Education of Malaysia reported in 2013 that, there were 107,191 students were caught for indiscipline in 2012, included truancy $(17,343$, or $16.18 \%)$, crime and delinquency (1432, or $13.36 \%)$, misbehavior (9926, or $9.26 \%)$, pornography $(3778$, or $3.52 \%$ ), vandalism (3630, or $3.39 \%)$, personal neatness (13926, or $12.99 \%)$, time wasting (10403, or 9.71\%), bullying (4159, or $3.88 \%)$, smoking (14298, or $13.34 \%$ ) and so forth. The statistics comprised of 26.91 percent from primary schools and 73.09 percent from secondary schools. In the same year of 2012, MOE of Malaysia revealed that a total of 1811 students were expelled, 6746 students were suspended, and, 16189 students were caned. Truancy showed the highest rate among the disciplinary problems of students. While bullying problems are escalating and draw attention from government and public in these recent years. According to De Voe, Kaffenberger, and Chandler (2005), bullying can be categorized as a breach of discipline in school. It is a disciplinary issue that has attracted attention from the society and mass media 
(Norshidah \& Khalim, 2014). Bullying is aggressive behavior and an issue that continues to draw attention from government, researchers, educators, parents and society. The increase in reported incidents of behavioral problems and delinquency clearly reflects that violations of human rights are rampant among students. Violence is a common occurrence in schools as indicated by numerous incidences of vandalism, gang fights, assaults, extortion, molestation, bullying and arson. Students' security, both physical and sexual, is threatened by these acts of violence (Suhakam, 2005).

There are a considerable number of studies on the disciplinary issues of students in Malaysia, however, most of these studies were carried out to identify the positive and negative behaviors in students (See, 2009), to determine the level and the factors contributing to the students discipline problems (Mastthurhah, Puteri Rohani Megat, \& Muhammad Sufi, 2013). This indicated the gap as lacks of research relate the root cause of discipline problems to mental health difficulties, and a new paradigm namely supportive disciplinary practice by using social-emotional learning (SEL) was introduced in this study to prevent and reduce the discipline problems. It is imperative that we stop to look at what is happening in school and the country, in terms of providing positive environment and quality experiences for children. In view of this, this study aims to examine some key issues in this area. This study is to view the disciplinary problems among students from the social-emotional perspective as well as to provide an alternative approach to tackle the problems. Besides, the researcher would like to raise the attention of Ministry of Education in this effort, to understand the root cause of discipline problems and thus enhance the students' inner part. This research might lead educators and parents to understand how critical these SEL and school environments are to the development of children. The study begins by exploring the call to rethink the current disciplinary practice which is based on reactive/punitive approach that underpins much of the contention. Following by discussion of the literature, focusing on three key questions: What is the root cause of discipline problems? What are the strategies to cope with the discipline problem? How SEL as a supportive disciplinary practice can help? These are the key issues to be discussed and as the consideration in developing practices, policy, and further research in this area.

\section{Rethinking School Discipline: An Overview of Current Disciplinary Practices}

The word discipline can be described into two distinct categories (American Heritage Dictionary of the English Language, 2000). The first category of definitions described discipline as a focus on a reliance on external controls, submission to authority and punishment. The punishment in first category of definition aimed to correct or train; to teach to obey rules or accept authority; to punish in order to gain control or enforce obedience; to impose order on; and a state of order based on submission to rules and authority (Dupper, 2010). This definition is cruel, coercive and reactive. The second category of definitions reflects the original Latin root of the word discipline - "to learn" (Morrison \& Skiba, 2001). This definition put in place which teaching and learning can take place. The definition can be described as the strategies that can be used to teach, train, coordinate, regulate and organize individuals and their activities in the school (Thornberg, 2008). This definition focused on development of self-control through teaching the problemsolving skills and learning more productive ways to express feelings. The training in this definition expected to produce specific character or pattern of behaviour, especially training that produces moral or mental improvement (Dupper, 2010). This definition is comprehensive, nurturing, liberating (Bechuke \& Debeila, 2012) and democratic. How have these disparate definitions of discipline impacted discipline policies and practices in Malaysia public schools over time? To curb the disciplinary issues, the Ministry of Education (MOE) of Malaysia introduce the punish-based disciplinary practice, and disseminates and enforces a comprehensive set of school rules and regulations. Schools provide learners with a copy of the school rules and regulations (Tie, 2014). School rules are enforced by means of a system of surveillance, penalties and punishments, which include demerit points, corporal punishment, alternative school placement, suspension and expulsion (Tie, 2014). At present, the method for maintaining school discipline is prescribed in the "School Disciplinary Procedure Handbook for Headmasters and Teachers". Schools and their teachers are expected to follow the guidelines outlined in the guidelines, especially in handing out punishments to misbehaving students.

Reactive and punitive approach is a common practice in handling the discipline problems in Malaysia. It is a negative discipline which describes a system where children are not allowed to participate in their own discipline. Children are seldom involved in procedures for complaints and reform (UNICEF Malaysia Communications, 2008). In fact, children have to be able to understand what their mistakes are and how they can make amends. Reactive and punitive approach in schools usually in the form of corporal 
(physical) or emotional punishment which carried out by teachers and other school staff, with the belief that this approach holds the correct means of disciplining, correcting, controlling, educating, or modifying the behavior of a student. However, research tells us that increasingly common in recent years, reliance on punitive approaches to discipline has proven largely ineffective, even counterproductive (NASP, 2002).

Corporal punishment is allowed in Malaysia, although the MOE of Malaysia has issued a clear set of guidelines regarding the application of corporal punishment. However, it is generally acknowledged, and has been demonstrated through research, that such punishment would result in emotional and psychological scarring due to humiliation, stigmatization, denigration, fear and ridicule (UNICEF Malaysia Communications, 2008). Studies have also shown that children who have experienced cruel, inhumane treatment are more susceptible to subject others to similar degrading actions. Many studies have shown that corporal punishment is positively related to bullying behaviors. Children who live in punitive environments rate higher on aggressive behaviors. Therefore, if corporal punishment is to prevail, so will bullying, and the vicious cycle of violence is perpetuated (UNICEF Malaysia Communications, 2008).

Many schools have adopted the punitive disciplinary practice approach to school discipline that usually entails the expulsion or suspension of students as an automatic consequence of serious acts of misconduct, particularly the fighting, delinquency and so forth. Furthermore, when practice the punitive approach, without consideration of the severity of the misbehavior involved, negative impact on student, and the school climate, harsh consequences are invoked automatically (NASP, 2002). Sprague and Horner (2006) also stated that using the reactive and punitive approaches to respond to problem behaviors is ineffective. The problems will reoccur and increase when punishing students with disruptive behavior without teaching them with the expected behavior and coping skills (Tran, 2007). Research repeatedly has demonstrated that suspension, expulsion and other punitive consequences are not the solution to dangerous and disruptive student behaviors (NASP, 2002). Research shows that getting suspended or expelled increases students' risk for falling into unproductive behavior, affecting their social-emotional development, academic performance, and life trajectories. According to American Institute of Research, evidence shows that students who are suspended or expelled from school as a means of punishment may be more vulnerable to the involvement in the delinquency.

Studies also find that positive approaches to school discipline at all ages can actually improve students' academic performance, and those students are less likely to become involved in the juvenile justice system or have need for behavioral services. In fact evidence, indicates that dangerous students do not become less dangerous to others when they are excluded from appropriate school settings; quite often they become more so. Some local authorities claimed that discipline should be taught, and need to have the enforcement of discipline rules in schools. As Bennathan (1992)'s statement above, schools who practices punishments when address students' discipline problems can increase the problems. Reactionary approaches, such as school suspension or expulsion briefly eliminate the problem in the school context, provide immediate and short relief of the problem, but consequently is ineffective as the problem is displaced to somewhere else, such as the home (Sprague \& Horner, 2006; Tran, 2007). As a whole, the punish-based disciplinary practices do not increase school safety. Schools rely too heavily on suspension and expulsion, and the practices neither improve school climate nor address the source of student alienation (NASP, 2002). Besides, the practices are related to a number of negative consequences, including increased rates of school dropout and discriminatory application of school discipline.

According to Bear (2011), there are multiple limitations of punish-based disciplinary practice. The effectiveness of this practice for the disciplinary problems is short-term but not the long-term, and punishment elicits short-term compliance but does not develop long-term self-discipline. Besides, this approach actually teaches students not to get caught, but not teaches them to differentiate the good and bad behaviors. Punishment fails to address the multiple factors that typically contribute to a student's misbehavior. It is regarded as using the simple, fast, and short-term solution to suppress or control a complex and long-term problem. Centre for Mental Health in Schools (2008) states that this approach is kind of approach that consists of a form of "social control aimed directly at reducing disruptive behavior" ( $p$. 6-4), while doing little to improve student motivation and engagement in learning or to develop intrinsic motivation." Although the researches tell us the truth of ineffectiveness and consequences of reactive and punitive approach in curbing the disciplinary problems, our government, educators, parents and society still show their over-reliance on it. This indicates the disparity between educational research and practice, as the evidence based effective methods for curbing the problems are not being implemented. All the 
related parties must rethink their discipline policies and seek new paradigm to address students' behavior problems. A possible new paradigm is looking at the use of SEL in managing discipline in schools.

Other Initiatives of Government in Curbing Disciplinary Problems: Other than reactive and punitive approach in curbing the disciplinary issues, government of Malaysia also introduced some other strategies. The government has called ten ministries to form a special body named Main Committee in Handling Student Discipline Symptoms ("Jawatankuasa Induk Menangani Gejala Disiplin") to plan strategies in reducing the disciplinary problems. The collaborations among those ministries could tell the discipline problems in Malaysia are alarming. Besides, there is collaboration among police and MOE in reducing the discipline problems, especially the truancy and delinquency problems. Some mass media portrayed the disciplinary issues as criminal cases. In fact, the discipline problems are kind of educational problems and should be curbed through educational strategies to cure the root instead of criminalized the behavior problem students. According to Deputy Minister of Health, YB Dato' Seri Dr. Hilmi Bin Haji Yahaya mentioned that MOH is cooperating with MOE to implement Healthy Mind Program (Program Minda Sihat) in schools. The program is conducted to determine the state of mental health of secondary school students by conducting mental health screening on symptoms of stress, anxiety and depression. The students who are detected to have severe symptoms of stress, anxiety or depression, appropriate interventions will be given. The Healthy Mind Program is a good initiative by the MOH to assess students' mental health states as many health problems may pass unnoticed in schools. It is also aimed to promote mental health among secondary school students in facing any life challenges and reduce the disciplinary issues. But prevention should be started in early stage of children, and there is a need to develop a well comprehensive plan in promoting the prevention and early intervention program from preschool, continues through to tertiary education.

Besides, MOE implements some strategies in education system to produce moral improvement and promote mental health wellbeing for students, and with an aim to reduce the disciplinary problems. One of the strategies is to integrate social and emotional elements into the curriculum through Moral Education ("Pendidikan Moral") and Health Education subjects ("Pendidikan Kesihatan"). But the implementation of this is still far from satisfactory due to the implementation plan is not well design, there is no real implementation and the teachers do not receive any training regarding social and emotional skills to teach. One study which carried out to investigate the teachers' attitudes and practices on SEL found that the teachers were not aware about the SEL integration in Health Education. Majority of them did not have SEL practices in their classroom (Lee, Yeo \& Hadijah, 2015). MOE also press on with school counselors to play a vital role in helping the students with discipline problems, through psychosocial and mental welfare program included hysteria case program, healthy mind program and sexual symptoms program. Other than these are the counseling sessions for students.

Our government has indeed called on schools to intervene through single educational programs such as anti-drugs campaign, exhibitions, seminars, campaigns and quizzes which contribute to discipline students, or promote moral, civic, and mental health for students, and some involving school clubs and Parent-Teacher Association (PTAs). However, those programs focus on one single problem or issue such as preventing substance use. But addressing single problem or issue is not efficient, and is not effective in reducing social-emotional problems or mental health difficulties (Merrell, Ervin, \& Gimpel, 2006). In addition, the problems associated with schools implementing multiple specific topic programs are typically very short; are not supported or reinforced in the home or daily lessons in schools; do not have chance to have consistent practice in daily life; and are often not regarded as important as the academic curriculum in schools (Payton et al., 2000). Furthermore, all the programs are interrelated, but they are scatter without systematic approaches in implementation. Instead of using traditional approaches, research has indicated a need and an understanding for more systematic preventative and proactive approaches for addressing school problems in terms of discipline problems, and how school problems or dysfunction is related to the larger system (Sheridan \& Gutkin, 2000). Consequently, schools need a proactive, inclusive approach, systematic, educative prevention and early intervention program that target all students to prevent and reduce behavior problems, while enhancing their social-emotional functioning and creating supportive school climate.

Understanding the Root Causes: Meeting the Developmental Needs of Children: Typically, government, educators, parents and society focused on discussing the contributing factors for disciplinary problems such as low socioeconomic status, peer influence, lack of parental guidance and 
religious instruction, school problems, and a shortage of schools and teachers. However, the parents, educators, government and public might not realize that the discipline problem is type of mental health difficulties and its root cause is the lacking of social-emotional competencies, and therefore without this awareness, they continue to encourage for the punish-based disciplinary practices. When parents and teachers expect children to conform to all the rules and regulations and work to their expectations especially academically and behaviourally, some children may just "disappoint" the adults. Any inappropriate strategies by the adults may end up bigger disappointments. Reactive and punitive approach is actually trying to suppress the symptoms instead of treating the root cause. Hence, there is a pressing need to replace punish-based disciplinary practices with supportive disciplinary practices or known as positive discipline strategies, which encourages children to develop self-control, confidence and respect for others through an ongoing educational process using non-violent approaches.

According to Goleman (1995), enormous researches claimed that emotional intelligence is critically important to children's psychosocial development. In contrast, lacking of emotional intelligence in children could be associated with various internalizing and externalizing behaviors. With lacking of emotional intelligence, one will develop lower levels of empathy, inability to manage emotion (Ciarrochi, Chan, \& Caputi, 2000), higher levels of alexithymia which is unable to express the emotion (Parker, William \& Aldridge, 2001), as well as higher levels of depression, somatic symptomatology, neuroticism, anxiety and stress (Dawda \& Hart, 2000). Consequently, for externalizing behavior, emotional intelligence deficiency are associated with poor academic performance (Bar-On, 1997), higher levels of tobacco and alcohol use (Trinidad \& Johnson, 2002), and higher levels of sexual offending. A student who possesses the social-emotional competencies able to cope with the challenges in life, despite the problems comes from his/her family, peer, school or society.

Besides, children who lack of appropriate social-emotional skills to cope with their life challenges are at risk for developing mental health difficulties or social-emotional problems (Kavale, Mathur, \& Mostert, 2004), and may have a negative attributional style that they interpret ambiguous social situations as threatening (De Castro, Veerman, Koops, Bosch \& Monshouwer, 2002). Besides, when they lack of the SE skills, they might have limited behavioural repertoires and might possess limited or no ability to control reactions to stressful situations when their emotion was provoke. Aggression is always the reactions in such instances, and therefore cause discipline problems in schools and place the children at particular risk of exclusion from schools (Cassen, Feinstein, \& Graham, 2009) and subsequently, from society (Christle, Jolivette, \& Nelson, 2005). Understand that the disciplinary problems are kind of the mental health difficulties in fact, the mental health issues, undoubtedly, to be gained critical attention. Mental health issues, including school children are a serious concern to our nation, but the prevalence of mental health problems in children can often co-occur or go unnoticed. Mental health issues are now a serious issue and the related problems in Malaysia are alarming. According to National Health and Morbidity Survey (2011), 12 percent of Malaysians with age 18 to 60 are suffering with some forms of mental illness, and the suicide rate increased from eight in the 1980s to nowadays nine to 12 persons for every 100,000 population. Besides, the mental health issues involving adolescence and children with age 15 and below showed mental health problems rose from 13 percent in year 1996 to 20 percent in year 2011. There is urgency and need to address in order to minimize the mental disorders occur (Che Rozaniza, Asbah, \& Rajalingam, 2013).

\section{Basic Philosophy and Approach: Coping Disciplinary Problems}

We need to understand the basic principles drawn from the theories, and realize evidence based and research based methods to cure from the root. According to Ministry of Education of Singapore, effective discipline is based on a consistent philosophy. Some basic philosophy and approach for developing positive discipline in students are:

- The goal of discipline is to teach or develop student self-control or self-discipline which is more student-centered and the goal is more long-term (Bear, 2011);

- Discipline is a learning process to develop students' thinking and moral faculties (MOE of Singapore);

- Focus is on the behavior, not the student as a bad person (centre for social and emotional education);

- A whole-school, multi-faceted, comprehensive, systematic approach is required. 
Self-discipline consists of five social-emotional competencies, and developing self discipline is important, as it connotes the critical notion of internalization. Through learning the self-discipline from SEL, the children are able to actively transform and endorse the internalized the values, standards, beliefs, and attitudes of their parents, teachers, and others in this society as their own (Bear, 2011). Many strategies focused solely on decreasing disruptive behavior, and reducing the disciplinary problems. In fact, a comprehensive program also emphasize on increasing the desirable behaviors, healthy emotion and mental health status, and improvements in cognitive thinking, skills and performance. There is a need to replace punitive in-school suspensions with discipline that focuses on student needs and helps students learn self-discipline. The students need to learn to develop intrinsic discipline, motivation and inner strength. The children need to enhance their social-emotional competencies through teaching the socialemotional skills in classroom by teachers via a holistic approach that includes a focus on affect, behaviour and cognitions, creating a supportive environment, and providing opportunities for students to practice good behaviour in their daily life.

According to NASP (2002), safer schools are more effective learning environments and students improve their behavior and performance when they are given an appropriate education in a conducive environment. And opportunities to forge relationships with caring adults, coupled with engaging curriculum, can prevent discipline problems. Positive solutions address student needs, environmental conditions, teacher interactions and matching students with curriculum. Social and emotional learning promotes the mental health of all children by helping schools focus on addressing children's skill development and creating a safe and caring school climate (Lynn, McKay \& Atkins, 2003). Socialemotional learning (SEL) contains the characteristics mentioned above, and thus is strongly recommended by the research to use in curbing the disciplinary problems.

A New Paradigm of School Discipline: Supportive-Preventive Model: The current discipline paradigm in Malaysia's public schools is ineffective and responds to student misbehavior by punishing and criminalizing students. Indeed, there is a pressing need for a fundamental paradigmatic shift in the way that we think about school discipline and the ways in which schools develop discipline policies and practices (Dupper, 2010). A new paradigm based on supportive-preventive model which is comprehensive, proactive, systematic, nurturing, and liberating namely SEL is thus introduced in this study. SEL is perhaps more important than ever as an essential component of school reform (Zins, Weissberg, Bloodworth, \&Walberg, 2004). SEL emphasizes relationships and the long-term goal of developing self-discipline (Bear, 2011). SEL addresses the social and emotional variables that place youth at risk for school failure in terms of lack of attachment to a significant adult and inability to regulate emotions; or promote school success such as ability to empathize with and work with others and effective conflict resolution skills (CASEL). As shown in Figure 1, SEL provides a common language and coordinating framework for communicating not just about SEL, but about a wide range of programs and teaching approaches commonly found in today's schools (Wilson, Gottfredson, \& Najaka, 2001). Once there is enhancement of social-emotional competencies and skills, positive relationship among teacherstudent and positive learning environment in classroom, discipline problems can be reduced or prevented. Research also tells us that SEL promotes young people's academic success, engagement, good behavior, cooperation with others, problem-solving abilities, health, and well being, while also preventing a variety of problems such as truancy, alcohol and drug use, bullying, and violence. Hence, discipline problems connected to mental health difficulties or problems, which can be alleviated if local authorities and educators can understand and address the root cause and come to a consensus recognizing that SEL can be best averted. 
Figure 1: SEL - A coordinating framework that provides synergy (Sources: CASEL, 2003)

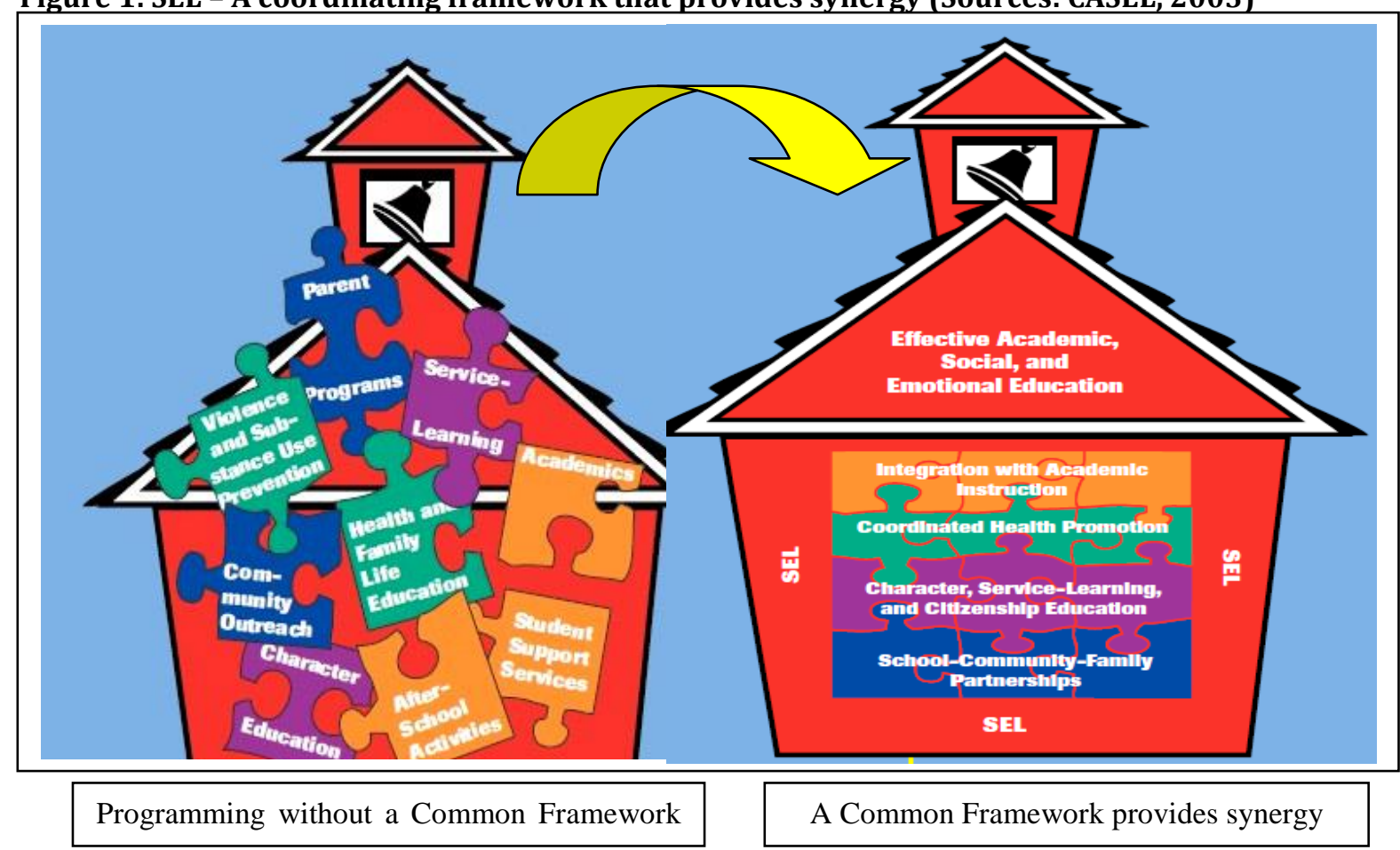

SEL is the process for the children to acquire the fundamental skills for life effectiveness. There are five core skills namely social-emotional competencies such as self-awareness, social-awareness, self management, relationship skills and responsible decision making. These skills provide fundamental in building emotion understanding and managing; empathy and developing caring for others; establishing and maintaining positive relationships; problem solving skills and making responsible decisions; and handling challenging situations effectively. SEL provides prerequisite skills necessary for children to be active and successful learners in school and positive peer and teacher interactions (CASEL, 2007). In SEL, thoughts, emotions, and behavior are viewed as equally important. SEL addresses social-emotional variables are related to students who are at risk for school failure, and provides educators with a common language and framework to organize their activities (Wilson et al., 2001). SEL, however, is an inclusive approach that covers the entire spectrum of SEC that helps children to be resilient and successful learners. SEL place more emphasis on active learning techniques, the generalization of skills across settings, and the development of social decision-making and problem solving skills that can be applied in many situations in life.

SEL targets the development of social and emotional competence in order to build children's protective factors and decrease the risk of behavioral and social problems. It is designed to promote social and emotional competence, prevent violence, aggression and other behavioral problems, lower externalizing (acting out) and internalizing (depression) problems, improve critical thinking skills and enhance the classroom climate. In addition, social-emotional wellbeing is interrelated to mental health and have a significant impact on mental health (Elder, Evans \& Nizette, 2013), as healthy emotion regulation is a cornerstone or basis of mental health (Vingerhoets, Nyklicek \& Denollet, 2008). SEL also helps children in preventing and reducing behavioral problems and mental health problems (NICE, 2013). Furthermore, SEL supports positive mental health and the abilities to develop psychologically, emotionally, intellectually, socially and spiritually (Barry, 2012). In other words, when children enhanced their socialemotional skills and developed social-emotional wellbeing through SEL, their mental health problems will be reduced and wellbeing will be thus promoted as well. SEL is a promising approach to lead the children to mental health wellbeing.

On the other hand, Merrell and Gueldner (2010) also suggested that SEL programs may be conceptualized as efforts at the primary prevention level to promote mental health and social-emotional development in schools. Social-emotional learning (SEL) promotes mental health and resilience, social-emotional and life skills, and to prevent negative life outcomes, through a broad range of methods and techniques in 
effective curricular programming, as an integral part of school program (Zins, Weissberg, Wang, \& Walberg, 2004). Besides, SEL can promote the mental health of all children by helping schools focus on addressing children's skill development and creating a safe and caring school climate (Lynn, et al., 2003). Past researches indicates that SEL programming for primary and secondary school students is a very promising approach in reducing behavior problems, discipline problems, promoting positive adjustment, and enhancing academic performance (Diekstra, 2008; Zins et al., 2004).

Durlak, Weissberg, Dymnicki, Taylor, and Schellinger (2011) completed a most recent and comprehensive analysis of the impact of universal SEL programs. Their research presents findings from a meta-analysis of 213 school-based and universal SEL programs, involving 270,034 students from kindergartens through high schools of different ages, from schools in urban, suburban, and rural settings, and from schools primarily serving ethnically and socio-economically diverse student bodies. Examined student outcomes in six areas:

$\begin{array}{ll}\text { - } & \text { social and emotional skills } \\ \text { - } & \text { attitudes toward self and others } \\ \text { - } & \text { cositive social behavior } \\ \text { - } & \text { emotional distress } \\ & \text { academic performance }\end{array}$

Positive findings with statistically significant were obtained in all six outcome categories at post (Payton et al, 2008). SEL programs have the potential to improve feelings of self-confidence and self-esteem, promote school bonding with positive attitudes and feelings toward school, improve school grades, reduce aggression, non-compliance, fewer conduct problems such as aggression, disruptiveness; lower levels of emotional distress such as anxiety, depressive symptoms, and reduce recreational drug use. Durlak et al. (2011) concluded that SEL programs demonstrated significant improvement in socialemotional skills, attitudes, behavior, emotional stress and academic performance. Effect sizes were largest for social and emotional skills. Their findings support the growing empirical evidence for the positive impact of SEL programs. Thus, noting the importance of SEL programs on student's capacities for learning (Thomas, Bierman \& Power, 2011), the policy-makers should recognize SEL as an important part of curriculum and integrate SEL in it as core subject or as important elements in subjects. Zins and Elias (2006) found that eight of the 11 most influential categories involved social and emotional factors, for instance, student-teacher social interactions, peer group, and classroom climate. Direct intervention in the psychological determinants of learning promises the most effective avenues of reform, which supports providing SEL in schools. Schools are such important central arena for health promotion and primary prevention, and SEL is a must addition to the education of students (Panju, 2008).

Reliable research revealed that SEL can be enhanced through the regular classroom teaching and learning process by teachers for every type of school and socio-culturally diverse children (CASEL, 2007). Through systematic instruction, SEL can be taught, modelled, practiced, and applied to diverse situations. Schools are a highly effective setting for teaching SEL skills (CASEL, 2007), as school and classroom environment is another inherently environmental variable other than home environment. Schools are increasingly seen as places for promoting good mental health through SEL, an enterprise that straddles the border between psychology and teaching (Shute, Slee, Murray-Harvey, \& Dix, 2012). Collaborative for Academic, Social, and Emotional Learning (CASEL) strongly recommended that schools use evidence-based classroom SEL programs as a core component of their efforts to promote students' social, emotional and academic learning. These programs such as PATHS, Caring School Community, 4Rs, Positive Action, and etc, have documented record of significantly improving school climate as well as students' behavior and academic performance. SEL programs with carefully evaluated to determine their quality and impact are effective to improve attitudes about school, prosocial behavior, and academic achievement, and reductions in substance use, mental health problems and aggression (Durlak et al., 2011).

School and classroom environment is another inherently environmental variable other than home environment. Students spend long hours in school to learn. It examines surroundings of student and school, including physical, sociocultural habits, patterns, and pressure that shape the social-emotional practice in the school. Within the school setting, SEL can best be accomplished through a layered approach of skills lesson, infusion into the curricula and classroom practices, and an environment of safety, respect, and caring which models SEL values. Systematic SEL programs begin in preschool, 
continues through high school, is intentionally linked to academics, and is an integral component of the school curriculum (Elias, 2003). Embedding social and emotional competence directly into academic curricula and make it as core subject, to train students through a holistic child development method will address social-emotional and academic achievement of students (Humphrey, Lendrum, \& Wigelsworth, 2010). There is urgency to have the SEL instruction, and the teachers need training in how to address SEL to manage their classroom effectively, to teach better, and to cope successfully with students who are challenging and reduces the amount of time spent on disciplinary action because the root of the problem is dealt with. Moreover, these teachers with such skills will be able to manage their own stress and solving problem with effectively and skilfully in their own lives (Zins, Bloodworth, Weissberg \& Walberg, 2004).

\section{Conclusion}

The type of intelligence required to handle this latter set of questions and problems is not acquired by memorizing rules and regulations, or through the use of technology. These challenges call for the development of students' social-emotional competencies. In fact, in facilitating social-emotional growth, the concern with one's awareness and how one intervenes should be emphasized. Reflection and understanding are the core basis for doing. But in Malaysia, the effort of developing positive discipline through SEL still lags behind. Nowadays, students are facing a more complex, economically challenging, and globally connected world. It is time for our country to move past false choices and ensure SEL is a core aspect of every child's education (Civic Enterprise, Bridgeland, Bruce \& Hariharan, 2013). By doing so, we can support teachers in their critical work that helps children develop self-discipline to curb the disciplinary problems and thrive not just as students, but also as leaders, dreamers, entrepreneurs, and citizens.

The researcher would like to raise the attention of MOH and MOE in this effort, to understand and enhance the students' inner part. In sum, we need to help children to successfully develop socialemotional competencies and mental health wellbeing, reduce behavioural problems, increase desirable behaviours by increasing protective factors, and lead to success in school and adult life. Thus, for longterm effects with the goal to develop self-discipline to curb the disciplinary problems, it is urging to understand the children's mental health state, and help them to live with healthy mental health through SEL. Effective mental health promotion, prevention and early intervention strategies play a key role in improving mental health in the country and that reducing the prevalence and impact of mental health problem and the disciplinary problems. In the research presented in this study has ideally gone some way toward elucidating the chances and challenges presented by the prospect of developing a SEL classroom or school. It is therefore important for further research to continue in this area.

\section{References}

Bar-On, R. (1997). The Emotional Quotient Inventory (EQ-i): A test of emotional intelligence. Toronto, Canada: Multi-Health Systems, Inc.

Barry, M. (2012). Mental health, social and emotional competencies and learning outcomes - fields of common interest and responsibility? Workshop on the role of mental health and social emotional learning in promoting educational attainment and preventing early school leaving, 9 October 2012. Directorate-General for Education and Culture, European Commission, Luxemburg.

Bear, G. (2011). Fostering positive school climate: developing supportive relationship and self-discipline. NASP. MD.

Bechuke, A. L. \& Debeila, J. R. (2012). Applying choice theory in fostering discipline: managing and modifying challenging learners' behaviours in South African schools. International Journal of Humanities and Social Science, 2(22), 240-255.

Bennathan, M. (1992). The care and education of troubled children. Therapeutic Care and Education, 1(1).

Blum, R. W. \& Libbey, H. P. (2004). School connectedness-Strengthening health and education outcomes for teenagers. Journal of School Health, 74, 229-299.

Cassen, R., Feinstein, L. \& Graham, P. (2009). Educational outcomes: Adversity and resilience. Social Policy and Society, 8(01), 73-85.

Center for Mental Health in Schools. (2008). Frameworks for Systemic Transformation of Student and Learning Supports. Los Angeles: Author. 
Che Rozaniza, A., Asbah, R. \& Rajalingam, P. (2013). Promoting Positive Mental Health among Students in Malaysia. Psychology and Behavioral Sciences, 2(2), 73-82.

Christle, C. A., Jolivette, K. \& Nelson, C. M. (2005). Breaking the school to prison pipeline: Identifying school risk and protective factors for youth delinquency, exceptionality. Special Education Journal, 13(2), 69-88. doi.10.1207/s15327035ex1302_2

Ciarrochi, J., Chan, A. \& Caputi, P. (2000). A critical evaluation of the emotional intelligence construct. Personality and Individual Differences, 29(2).

Civic Enterprises., Bridgeland, J., Bruce, M. \& Hariharan, (2013). The Missing Piece: A National Teacher Survey on How Social and Emotional Learning Can Empower Children and Transform Schools. Collaborative for Academic, Social, and Emotional Learning. Chicago: Author.

Collaborative for Academic Social and Emotional Learning (CASEL). (2007). Promoting Children's Success in School and Life. Chicago, IL: Author.

Dawda, D. \& Hart, S. D. (2000). Assessing emotional intelligence: Reliability and validity of the Bar on Emotional Quotient Inventory (EQ-I) in university students. Personality and Individual Differences, 28.

De Castro, O. B., Veerman, J. W., Koops, W., Bosch, J. D. \& Monshouwer, H. J. (2002). Hostile attribution of intent and aggressive behavior: A Meta analysis. Child Development, 73, 916-934.

DeVoe, J. F., Kaffenberger, S. \& Chandler, K. (2005). Student reports of bullying: results from the 2001 school crime supplement to the national crime victimization survey. Statistical Analysis Report. National Centre for Education Statistics. Institute of Education Sciences. U. S. Department of Education.

Diekstra, R. F. W. (2008). Effectiveness of school-based social and emotional education programme worldwide. In Social and emotional education: An international analysis (pp. 255-312). Santender, Spain: Foundation Marcelino Botin.

Dupper, D. R. (2010). A New Model of School Discipline: Engaging Students and Preventing Behavior Problems. Oxford University Press, Inc. New York.

Durlak, J. A., Weissberg, R. P., Dymnicki, A. B., Taylor, R. D. \& Schellinger, K. B. (2011). The impact of enhancing students' social and emotional learning: A meta-analysis of school-based universal interventions. Child Development, 82, 405-432.

Elder, R., Evans, K. \& Nizette, D. (2013). Psychiatric and mental health nursing $3^{\text {rd }}$ Edition. Elsevier, Australia.

Elias, M. J. (2003). Academic and social-emotional learning. Geneva: International Academy of Education and the International Bureau of Education.

Goleman, D. (1995). Emotional intelligence. New York: Bantam Books.

Humphrey, N., Lendrum, A. \& Wigelsworth, M. (2010). Social and emotional aspects of learning (SEAL) program in secondary schools: national evaluation. School of Education, University of Manchester. United Kingdom.

Kavale, K. A., Mathur, S. R. \& Mostert, M. P. (2004). Social skills training and teaching social behavior to students with emotional and behavioral disorders. In R. B. Rutherford, M. M. Quinn, \& S. R. Mathur (Eds.), Handbook of research in emotional and behavioral disorders (pp. 446-61). New York: The Guilford Press.

Lee, M. C., Yeo, K. J. \& Hadijah, J. (2015). Teachers' Attitudes and Practices on Social-Emotional Learning in Classroom. In Press. $1^{\text {st }}$ International Conference on Educational Studies (ICES) 2015, Johor Bahru, Malaysia, 3-4 June.

Lynn, C. J., McKay, M. M. \& Atkins, M. S. (2003). School social work: Meeting the mental health needs of 6. Students through collaboration with teachers. Children \& Schools, 25(4), 197-209.

Mastthurhah, I., Puteri Rohani Megat, A. R. \& Muhammad Sufi, M. Y. (2013). Educational Strategies to Develop Discipline among Students from the Islamic Perspectives. Procedia - Social and Behavioral Sciences, 107, 80-87.

Merrell, K. W., Ervin, R. A. \& Gimpel, G. A. (2006). School psychology for the 21st century. New York: Guilford Press.

Merrell, K. M. \& Gueldner, B. A. (2010). Social and Emotional Learning in the Classroom: Promoting Mental Health and Academic Success. New York, NY: Guilford Publications.

Morrison, G. M. \& Skiba, R. (2001). Promises and perils. Psychology in the Schools, 38, 173-184.

National Association of School Psychologists (NASP). (2002). Fair and Effective Discipline for All Students: Best Practice Strategies for Educators. MD.

NICE (National Institute for Health and Care Excellence). (2013). Social and emotional wellbeing for children and young people. Local government briefings. 25 September 2013. United Kingdom. 
Norshidah, M. S., \& Khalim, Z. (2014). Bullying among secondary school students in Malaysia: a case study. International Education Studies, 7(13), 184-191.

Panju, M. (2008). 7 Successful Strategies to Promote Emotional Intelligence in the Classroom. Continuum International Publishing Group. New York.

Parker, H., William, L. \& Aldridge, J. (2001). The normalization of 'sensible' recreational drug use: further evidence from the North West England longitudinal study. SAGE Publications. Thousand Oaks, London.

Payton, J., Weissberg, R. P., Durlak, J. A., Dymnicki, A. B., Taylor, R. D., Schellinger, K. B. \& Pachan, M. (2008). The positive impact of social and emotional learning for kindergarten to eighth-grade students: Findings from three scientific reviews. The Collaborative for Academic, Social and Emotional Learning (CASEL).

Payton, J. W., Wardlaw, D. M., Graczyk, P., Bloodworth, M. R., Tompsett, C. J. \& Weissberg, R. P. (2000). Social and Emotional Learning: A Framework for Promoting Mental Health and Reducing Risk Behavior in Children and Youth. Journal of School Health, 70(5), 179-185.

See C. M. (2009). Psychological profile inventory for adolescents in Malaysia. Asia Pacific Journal of Educators and Education, 25, 137-151.

Sheridan, S. M. \& Gutkin, T. B. (2000). The Ecology of School Psychology: Examining and Changing Our Paradigm for the 21st Century. School Psychology Review, 29(4), 485-502.

Shute, R. H., Slee, P. T., Murray-Harvey, R. \& Dix, K. L. (2012). Mental health and wellbeing: Educational perspectives. Adelaide: Shannon Research Press.

Sprague, J. R. \& Horner, R. H. (2006). School wide positive behavioral supports. In S. R. Jimerson \& M. J. Furlong (Eds.), The handbook of school violence and school safety from research to practice. Lawrence Erlbaum: Mahwah, NJ.

Suhakam. (2005). Assessing Knowledge of Human Rights Practices in Malaysian Schools. Human Rights Education in Asian Schools, 8, 139-149.

Thomas, D. E., Bierman, K. L. \& Power, C. J. (2011). The influence of classroom aggression and classroom climate on aggressive-disruptive behavior. Child Development, 82(3), 751-757.

Thornberg, R. (2008). School children are reasoning about school rules. Research papers in Education, 23(1), 37-52.

Tie, F. H. (2014). The Law regulating student discipline in Malaysia. In C.J. Russo, I.J.O. Oosthuizen \& C.C. Wolhuter (eds.), International perspectives on student behaviour: what we can learn. Littlefield and Rowman, New York.

Tran, O. K. (2007). Promoting social and emotional learning in schools: An investigation of massed versus distributed practices schedules and social validity of the strong kids curriculum in late elementary aged students. Doctor of Philosophy, University of Oregon, USA.

Trinidad, D. R. \& Johnson, C. A. (2002). The association between emotional intelligence and early adolescent tobacco and alcohol use. Personality \& Individual Difference, 32, 95-105.

UNICEF Malaysia Communications. (2008). Fact Sheet: Positive Discipline. Teacher Education on Bullying Prevention and Positive Discipline. A project by UNICEF, HELP University College and the Ministry of Education.

Vingerhoets, A., Nyklicek, I. \& Denollet, J. (2008). Emotion regulation: Conceptual and clinical issues. New York, NY: Springer Science.

Wilson, D. B., Gottfredson, D. C. \& Najaka, S. S. (2001). School-based prevention of problem behaviors: A meta-analysis. Journal of Quantitative Criminology, 17, 247-272.

Zins, J. E. \& Elias, M. J. (2006). Social and emotional learning. In G. G. Bear \& K. M. Minke (Eds.), Children's needs III: Development, prevention, and intervention (pp.1-13). Bethesda, MD: National Association of School Psychologists.

Zins, J. E., Weissberg, R. P., Wang, M. C. \& Walberg, H. J. (Eds.). (2004). Building academic success on social and emotional learning: What does the research say? New York: Teachers College Press.

Zins, J., Weissberg, R. P., Bloodworth, M. R. \& Walberg, H. J. (Eds.). 2004. Building Academic Success on Social-Emotional Learning: What Does the Research Say? New York: Teacher's College Press. 